\title{
Physical Exercise for Secondary Osteoporosis
}

\author{
Daniel Santa Mina ${ }^{*}, 1,2$, Shabbir M.H. Alibhai ${ }^{3,4}$, Andrew G. Matthew ${ }^{1}$, Crissa L. Guglietti ${ }^{2}$, \\ Shalini Moonsammy ${ }^{2}$, John Trachtenberg ${ }^{1,3}$ and Paul G. Ritvo ${ }^{2,5}$ \\ ${ }^{I}$ Department of Surgical Oncology, Princess Margaret Hospital, Toronto, Ontario, Canada \\ ${ }^{2}$ School of Kinesiology and Health Science, York University, Toronto, Ontario, Canada \\ ${ }^{3}$ Department of Medicine, University of Toronto, Toronto, Ontario, Canada \\ ${ }^{4}$ Department of Medicine, University Health Network, Toronto, Ontario, Canada \\ ${ }^{5}$ Cancer Care Ontario, Toronto, Ontario, Canada
}

\begin{abstract}
Bone loss caused by an underlying medical illness or associated treatment is often termed secondary osteoporosis and is a growing concern for a variety of patients. Exercise has demonstrated efficacy in maintaining bone health for individuals with age-related osteoporosis and its application to other clinical populations with specific interest in preserving bones is being increasingly explored. While there are many causes of secondary osteoporosis, only a few clinical populations have been studied for the role of exercise as a non-pharmacologic approach to bone preservation. This article briefly reviews secondary osteoporosis and the effect of exercise on bone health, while highlighting the current exercise intervention literature on bone outcomes for several clinical populations.
\end{abstract}

Keywords: Bone, exercise, physical activity, secondary osteoporosis.

\section{INTRODUCTION}

Given the multiple, significant functions of bone, its healthy development and maintenance are of great importance. Compromised bone health is a growing concern for researchers and clinicians due to the personal, social, and economic burden associated with the treatment of fractures and related comorbidities [1-3]. Unfortunately, many persons with chronic disease and those undergoing treatments for acute conditions may be susceptible to secondary osteoporosis. Exercise has demonstrated significant bone-related benefits in healthy children and adults [4-9], and may be the most readily modified lifestyle factor that can contribute to bone health and reduction in fracture risk in clinical populations [10-12]. This paper provides a scoping review of the current evidence for exercise on bone outcomes in patients with or at risk for secondary osteoporosis.

\section{SECONDARY OSTEOPOROSIS}

Secondary osteoporosis is bone loss and increased fracture risk due to underlying morbidity and/or associated treatment [13]. For many individuals, this bone loss is exacerbated by poor dietary intake of vitamin $\mathrm{D}$ or calcium, and/or reductions in physical activity and exercise due to disease or treatment-related fatigue or malaise [14-17]. The World Health Organization (WHO) classifies osteoporosis as a $\mathrm{BMD}<2.5$ standard deviations below the mean of healthy

*Address correspondence to this author at the University Health Network (Toronto General Hospital), Eaton North, $9^{\text {th }}$ Floor, Rm 9-212, 200 Elizabeth Street, Toronto, Ontario, M5G 2C4, Canada; Tel: 416-340-4800, Ext. 3957; Fax: 416-340-4739; E-mail: Daniel.Sta.Mina@uhn.ca young women $[18,19]$ and has supplemented this criterion with the Fracture Risk Assessment Tool to further stratify fracture risk [20]. The annual costs associated with osteoporotic fractures are approximately $\$ 17.9$ billion (USD) in the United States [2], however the specific costs associated with osteoporotic fractures that are secondary to underlying morbidity is unknown. Given the substantial physical, social, and economic costs associated with osteoporosis, researchers and clinicians are challenged to find ways to preserve and/or recover bone health.

Many disorders and treatments well-known to cause secondary osteoporosis, including: hypogonadism (idiopathic or induced chemically or surgically for cancer treatment) [2126], glucocorticoid use [27-29], hyperthyroidism [30-32], Cushing's disease $[33,34]$, and diabetes mellitus $[35,36]$ (See Table 1 for a summary of mechanisms leading to reduced BMD and fracture risk in selected populations). Beyond these, there is a growing list of etiologies for secondary osteoporosis, that have stimulated several reviews in this field [37-42]. For many medical conditions, secondary osteoporosis screening may not be included in standard care, possibly leading to later diagnoses (e.g. following a fracture) and delayed treatment [37, 39]. Medical management of secondary osteoporosis targets the primary diagnosis, and strives to prevent fractures with interventions designed to improve bone density [39]. Treatment strategies for osteoporosis secondary to endocrine diseases typically focus on recovering normal levels of hormones through surgery, radiation, or pharmacologic intervention [39]. Age-related sex hormone deficiency is often treated with hormonereplacement therapy, but this treatment approach must be weighed against the risk of sex-hormone-linked cancers, such as breast and prostate cancer [39]. Bisphosphonates are 
frequently prescribed for secondary osteoporosis [43] with common indications in patients receiving glucocorticoid therapy [29], androgen deprivation therapy (ADT) for prostate cancer [44, 45], and for breast cancer patients receiving aromatase inhibitors or experiencing chemotherapy-induced ovarian failure [46-48]. RANKL inhibitors (e.g. Denosumab) have generated increased interest for their bone preserving and enhancing characteristics, and have shown therapeutic benefit for cancer treatment-induced bone loss (CTIBL) [4951]. In addition to pharmacologic approaches, recommendations for increased vitamin D and/or calcium intake are common, despite inconclusive evidence regarding their efficacy [52]. However, a recent Cochrane review of five randomized trials (aggregate sample of $n=274$ ) by Homik et al. found that lumbar and radial BMD was improved 2 years after initiating vitamin $\mathrm{D}$ and calcium supplementation in patients receiving glucocorticoid treatment [53]. Current general recommendations for daily consumption are $800-1200 \mathrm{mg} /$ day and $800 \mathrm{IU} /$ day, for calcium and vitamin $\mathrm{D}$, respectively [39].

Beyond dietary and drug treatments, exercise has been increasingly recommended for its bone-stimulating properties for the general population and individuals with primary or secondary osteoporosis. For healthy adults, the American College of Sports Medicine (ACSM) makes the following exercise recommendations for bone preservation [10]:

Frequency: Weight-bearing, aerobic activities 3-5 days per week; resistance training and high-impact/plyometric activities 2-3 days per week.

Intensity: Moderate to high bone-loading forces.

Time: 30-60 minutes per day of aerobic and/or resistance exercises.

For patients with primary osteopenia or osteoporosis, a systematic review of 28 randomized controlled trials (RCTs), observed a reduction in falls and fall-related fractures in exercising patients in interventions that ranged from 10 weeks to 30 months (median duration $=26$ weeks) [54]. Improvements in BMD ranged from $0.5 \%$ to $10.2 \%$ (mean improvement of approximately $2.5 \%$ ), however, the most consistent, and arguably most important, finding throughout the trials is that exercise preserves BMD in low-BMD patients relative to non-exercising participants and improves muscular strength, endurance, and balance. These findings cumulatively confer reductions in fall and fracture risk. These important findings demonstrate that while exercise may not always provide direct or sizeable benefit to BMD in people with primary osteopenia or osteoporosis, it can mitigate BMD decline and prevent falls and/or fractures. These findings also underscore exercise guidelines for patients with primary osteoporosis that emphasize weightbearing and resistance exercises in addition to balance training and avoidance of extreme flexion/extension/twisting that may cause fractures [55].

Amongst the guidelines for exercise training in various clinical populations, few discuss exercise considerations for secondary osteoporosis and fracture risk (See Table 2 for general clinical exercise recommendations and proposed considerations for secondary osteoporosis). While bonespecific exercise guidelines may not be necessary for every clinical group, a deeper understanding of the interaction between primary morbidity, secondary osteoporosis, and exercise is warranted as clinicians explore novel and holistic methods of BMD preservation and fall/fracture prevention. In the sections that follow, we briefly review the current literature on exercise interventions for the common causes of secondary osteoporosis.

\section{EXERCISE AND CANCER-RELATED BONE LOSS}

Cancer affects bone health through: a) direct effects of the cancer itself (osteosarcomas or metastatic lesions), b) toxic effects of cancer therapies that affect bone modeling processes, c) reductions of calcium and vitamin D absorption, or d) sedentary lifestyles related to cancer-related fatigue $[16,17,56]$. CTIBL is primarily associated with reduced circulating androgens and estrogens via induced hypogonadism in men and women associated with chemotherapy, hormonal therapy (including surgical castration) and irradiation $[16,17,56,57]$. Chemotherapeutic agents, such as doxorubicin, methotrexate, and cyclophosphamide directly reduce bone mineral content (BMC) by increasing bone resorption and reducing bone formation $[17,57]$. Radiation and other systemic drugs, such as glucocorticoids and cyclosporine, have also been correlated with bone loss in cancer patients [17, 57]. For gastric carcinoma patients, bowel and intestinal resection may also be associated with CTIBL resulting from calcium and vitamin $\mathrm{D}$ deficiency (due to limited dairy intake) as well as poor absorption of these nutrients [17, 57]. For hormone dependent cancers, such as cancers of the breast and prostate, controlling or completely diminishing sex hormones is a mainstay of treatment that results in significant CTIBL. Accordingly, these cancers have received a bulk of the attention in terms of research with exercise and bone outcomes.

\section{Exercise and Cancer-Related Bone Loss in Women with Breast Cancer}

Therapies for breast cancer, including surgery, chemotherapy, radiation therapy, and hormone therapy (i.e. antiestrogens, aromatase inhibitors, and selective estrogen receptor modulators) are associated with several deleterious effects on body composition, such as increased total weight and fat mass as well as decreased lean mass and BMD, with negative survival and quality of life implications [17, 58-62]. Adjuvant hormone therapy for breast cancer is associated with premature menopause in as many as $40 \%$ of females less than 40 years and $50-100 \%$ of females greater than 40 years[63]. Early onset menopause, due to luteinizing hormone-releasing hormone agonists (LHRHa) and aromatase inhibitors, is related to significant bone degradation, via increased osteoclast activity [64-66]. Interestingly, tamoxifen, a frequently prescribed anti-estrogen, appears to preserve BMD in postmenopausal women and degrades BMD in premenopausal women, of which, the mechanisms are poorly understood $[14,17,26,67,68]$.

A growing body of research describes numerous benefits for breast cancer patients who exercise during and after treatment $[69,70]$. More than 70 controlled trials have examined exercise in breast cancer patients and survivors; 
however, only seven have examined bone health outcomes [71-77]. Studies assessing bone health in breast cancer patients have typically included women who are peri- or postmenopausal [71-76, 78], are at least 6 months post primary chemotherapy or radiation therapy [71, 72, 75-77] and receiving adjuvant selective estrogen receptor modulators or aromatase inhibitors [71-77]. Three RCTs showed that exercise may prevent the typical loss of BMD experienced in patients that are not exercising [71, 77, 78]. Bisphosphonates appear to provide better treatment for CTIBL in breast cancer patients than exercise [74], however exercise plus bisphosphonates appears to be better than bisphosphonates alone [76].

In a pre- post-test design, Knobf and colleagues assessed the effects of a 16 to 24 week, weight-loaded aerobic exercise intervention for 26 Stage I and II pre- or perimenopausal breast cancer patients who had completed chemotherapy and/or radiation therapy (27\% of whom were also undergoing adjuvant hormonal therapy with tamoxifen or aromatase inhibitors) [72]. The supervised, communitybased intervention consisted of treadmill walking while wearing a weight belt and weighted backpack, three times per week. After 12 weeks, the weighted backpack was removed from the intervention protocol due to the exacerbation of arm lymphedema in one patient. No significant changes from baseline to 12 or 24 weeks were observed for body composition (lean mass, fat mass, or weight) or serum biomarkers of bone remodeling (osteocalcin and N-terminal propeptides of type I collagen [NTX]). No changes were observed for lean muscle mass, body fat percentage, or BMD as assessed by dual energy $\mathrm{x}$-ray absorptiometry (DEXA). As changes in serum markers of bone remodeling and BMD were absent, this study reconfirms the bone-maintaining properties of weight bearing aerobic exercise. Moreover, the finding of arm lymphedema exacerbation, which may be associated with wearing a weighted backpack, has important implications for cancer-exercise specialists, particularly those motivated to increase strain magnitude to aid bone maintenance and recovery.

A single blinded RCT by Winters-Stone and colleagues studied the effect of a 1-year moderate-intensity resistance plus impact-loading exercise intervention versus progressive stretching (control intervention) in 106 women who were 1 year post treatment for early stage breast cancer [77]. The impact loading exercises involved two-footed, 1 inch jumps, with weighted vests. The primary endpoints for this study were body composition parameters (BMD, lean mass, and fat mass) using DEXA. Additionally, the investigators assessed systemic markers of bone turnover (serum osteocalcin and urinary deoxypyrodiniline crosslinks). At the 12-month follow-up, participants in the exercise intervention maintained lumbar spine BMD compared to losses observed in control subjects $(0.47 \%$ change $v s .-2.13 \%$ change, $\mathrm{p}<0.01)$. There were no between-group differences in total body or hip BMD. Interestingly, osteocalcin, a marker of bone formation, improved more in the control group than in the exercise group $(1.59 \%$ change $v s .26 .5 \%$ change, $\mathrm{p}=0.01)$. They also found that the exercise significantly improved lean mass in women receiving adjuvant hormone therapy (aromatase inhibitors), compared to non-exercising partici- pants who were not receiving hormone therapy. These results suggest that fracture risk in the lumbar spine can be reduced with resistance training and plyometric-type exercises, but hip and total body BMD may be unresponsive to this particular intervention. The authors suggest that loading in unique/novel planes (rather than vertical), as well as exercise at a higher intensity or longer durations, may be required for adequate bone remodeling to occur in the hip [77].

Schwartz and colleagues were the first to examine the effect of exercise on bone health outcomes specifically for breast cancer patients currently receiving chemotherapy [78]. In their three-arm RCT, 66 stage I-III breast cancer patients were assigned to usual care, resistance exercise or aerobic exercise for 6 months. Subjects in the aerobic exercise intervention were encouraged to perform aerobic exercise of their preference, such as walking or jogging, for 15 to 30 minutes, four times per week at a moderate intensity. Resistance training subjects were instructed to complete four upper and four lower body exercises using resistance bands for two sets of 8-10 repetitions, four times per week. Participants in the usual care control group were neither encouraged nor discouraged from exercising. Based on an intention-to-treat analysis, only aerobic training had a significantly higher (as measured by percent change) lumbar spine BMD compared to controls (mean difference $=7.1$; $95 \% \mathrm{CI}=-1.98-0.14 ; \mathrm{p}=0.02$ ). Similar differences between the aerobic exercise group and control subjects were observed in analyses that controlled for menopausal status. It is also important to note that, although all participants started the trial with healthy BMD levels (i.e. not osteopenic or osteoporotic), seventeen women were osteopenic or osteoporotic by the end of the trial. While the results of this trial suggest that weight bearing aerobic exercise may be more beneficial than resistance training when compared to usual care, the intensity of the resistance training (using resistance bands) likely lacked sufficient loading to induce physiologic changes to the bone. Accordingly, it may not compare well to weight bearing aerobic activities. More research that specifically assesses the effects on bone health and fractures is warranted given these promising findings. Interestingly, two studies failed to describe BMD outcomes despite assessing body composition with DEXA [79, 80]. This non-reporting of BMD outcomes is likely due to null findings which may be attributed to the fact that patients generally had healthy BMD levels at the onset of these trials. To critically address this issue, stratified analysis of patients with and without impaired BMD is required.

The examination of bone health in breast cancer patients is of growing interest, but remains scant in the collective body of exercise and breast cancer research. Interesting findings have been produced by Schwartz and Winter-Stone suggest the lumbar spine may be particularly amenable to weight-bearing exercise, while hip BMD may require different approaches to exercise training to facilitate BMD preservation or improvement. This emerging literature has, for the most part, utilized strong methodological design and DEXA to assess changes in BMD with exercise. Future studies are required to determine the effect of different exercise patterns with and without the use of bisphosphonates on breast cancer patients with osteoporosis. 


\section{Exercise and Cancer-Related Bone Loss in Men with Prostate Cancer}

In men, circulating androgens and estrogen play fundamental roles in the maintenance of BMD $[22,68]$. For many men with prostate cancer, hormonal therapy via LHRHa, orchiectomy and anti-androgens is a prevalent form of treatment. The induced hypogonadism by LHRHa and orchiectomy has significant negative effects on BMD, which have been widely examined [21, 24, 81-91]. ADT can cause BMD reductions of $6.6 \%$ and $10 \%$ over the first two years after LHRHa and orchiectomy, respectively; with further reductions of $2 \%$ per year thereafter [85]. Shahinian et al. examined the records of 50,613 prostate cancer patients from the Surveillance, Epidemiology, and End Results (SEER) database and found that men that survived for 5 years or more post-diagnosis had a fracture risk of $19.4 \%$ if they received androgen deprivation therapy (ADT) versus $12.6 \%$ for men that did not receive ADT [24]. Moreover, a history of skeletal fractures (of the hip, spine, or extremity) were negatively associated with survival in a prospective cohort study of 195 men receiving ADT [90].

Given the prevalence and severity of bone degradation in this population, several authors have suggested exercise as a possible lifestyle approach to mitigate this side effect (e.g. $[21,81,85,92])$. Despite the recommendations for exercise, in a recent observational study, only 7 of $66(11 \%)$ patients undergoing ADT reported discussing lifestyle changes, including exercise, with their physician [93], a finding that contradicts other reports that urologists and radiation oncologists report discussing such lifestyle interventions with ADT-treated patients a majority $(\sim 60-80 \%)$ of the time [94]. The profound effect of hormone therapy on bone health in prostate cancer patients suggests that more studies should examine exercise as a bone preservation intervention in this population. To date, only Galvao and colleagues have reported on bone outcomes for prostate cancer patients in their 20-week, intensive resistance exercise program [95]. In this pre- post-test design of ten androgen-deprived patients, participants were trained with 12 upper- and lower-body exercises at 6- to 12-repetition maximum, including: chest press, seated row, shoulder press, latissimus pull-down, triceps extension, biceps curl, leg press, squat, leg extension, leg curl, abdominal crunch, and back extension (using machines). The results of the study showed significant improvements from baseline in muscle strength (upper and lower body measures; $\mathrm{p}<0.001$ ), functional fitness measures $(\mathrm{p}<0.05)$, and quadriceps thickness $(\mathrm{p}<0.05)$. In this trial, $\mathrm{BMC}$ and BMD (measured by DEXA) were preserved over the 20 -week study duration. Also notable was that the high intensity exercise did not affect prostate specific antigen (PSA), growth hormone, or free testosterone levels, which are markers of disease progression, suggesting that exercise is safe in men with induced hypogonadism in terms of prostate cancer progression. A follow-up study by this group is currently being conducted by the same group, with the primary endpoints of total body, hip, and vertebral BMD measured by DEXA in a multi-centre, RCT of 195 men receiving ADT for prostate cancer [96]. This is a potential landmark study, in that it may be the first to examine the effects of exercise in an RCT sufficiently powered to assess bone changes in non-osteoporotic men undergoing hormone therapy for prostate cancer.

Two additional studies evaluated exercise interventions with prostate cancer patients using DEXA for body composition, but did not report BMD or BMC as primary or secondary outcomes [97, 98]. Galvao and colleagues conducted a RCT examining the effects of a mixed-modality (resistance and aerobic exercise training) for 57 prostate cancer patients receiving ADT [97]. Although they noted significant improvements in lean mass for intervention subjects compared to controls measured by DEXA $(p<0.05)$, BMD findings were not reported. However, they did report modest improvements in balance (measured by the 6 meter backward walk test) $(\mathrm{p}=0.039)$ and the Activities-Specific Balance Confidence Scale $(p=0.061)$ which may have preventative effects on falls and fractures. Segal and colleagues compared aerobic exercise training and resistance exercise training over 24 weeks in prostate cancer patients undergoing radiation therapy, of whom more than $60 \%$ were also on adjuvant ADT [98]. Resistance training proved more effective than aerobic exercise training when compared to controls, in terms of aerobic and musculoskeletal fitness, quality of life, and body fat percentage measured by DEXA $(p<0.05)$. Again, bone outcomes were not reported. Collectively, this young body of literature suggests that exercise can produce muscular benefits that may reduce falls and subsequent fractures. Moreover, early findings suggest that there is bone preservation in exercising ADT-treated prostate cancer patients, which will be thoroughly investigated in the current trial by Newton [96].

\section{Exercise and Acute Lymphoblastic Leukemia}

Children with acute lymphoblastic leukemia (ALL) often present with osteoporosis-range BMD scores related to their chemotherapy, which may persist into adulthood [99, 100]. To preserve BMD in childhood ALL survivors, Hartman et al., examined the effects of a 2-year exercise program on total body and lumbar spine BMD as well as motor performance and ankle flexibility in 67 children and adolescents with ALL (median age of 5.4 years) [101]. In this RCT, exercising subjects completed hand, leg, and ankle function exercises, as well as short-burst, high-intensity activities (such as jumping) in a home-based format with follow-ups every 6 weeks. Endpoints were measured at baseline (time of diagnosis), 8 and 12 months after diagnosis, discontinuation of treatment ( 2 years after diagnosis), and 1 year after discontinuation of treatment (3 years after diagnosis). Only $48 \%$ of the study group exercised more than once per week. The results of the trial indicated no between-groups differences for BMD or motor performance at any of the follow-ups. The authors surmised that the lack of effect on bone and performance outcomes was likely due to poor adherence in the exercise group, a noted challenge in many cancer-exercise trials. Furthermore, the challenge of engaging a very young (median age $=5.8$ years, age range $=1.7$ 17.1 years) population in routine, controlled exercises, likely rests with determination and attention of their parents, further complicating this approach.

This area deserves further investigation since children treated for ALL are likely to experience lifelong BMD 
challenges with heightened risk for fractures. The dearth of literature in this area is complicated by the young age of the cohort combined with the common exercise adherence problems of cancer exercise trials. Thus, creating age-appropriate exercise interventions that are conducive to adherence during cancer treatment are necessary to properly measure the impact of exercise on BMD in children. Subsequently, examination of exercise in adults with a history of childhood ALL is warranted to assess whether physical activity can beneficially augment fracture risk in this population.

\section{EXERCISE AND BONE HEALTH FOR HEART TRANSPLANT RECIPIENTS}

For patients undergoing heart transplantation, immunosuppression with glucocorticoids is a standard of care to facilitate host acceptance of the allograft and is associated with significant bone loss [102, 103]. Moreover, studies have demonstrated that $44 \%$ of all heart transplant recipients (HTR) have long bone fractures within the early post-operative period, and $35 \%$ of HTRs have non-traumatic, compression fractures of the lumbar vertebrae likely due to compromised bone integrity [102, 104]. Glucocorticoids affect vitamin $\mathrm{D}$ metabolism and decrease calcium absorption while increasing calcium excretion, causing a net loss in calcium and stimulating parathyroid hormone, an agonist of bone resorption [104, 105].

Accordingly, researchers have sought to identify mechanisms by which the compromised bone health and fracture risk in HTRs can be mitigated [106, 107]. Braith and colleagues randomly assigned 16 HTRs to either a 6-month resistance exercise program or a usual care, control group. Total body, femoral neck, and lumbar spine BMD was assessed by DEXA at baseline, 2 months following transplantation (at the beginning of the exercise intervention), and 3 and 6 months after the initiation of the exercise intervention. The exercise intervention consisted of supervised resistance exercise training, two days per week for 6 months, progressing from $50 \%$ of 1 repetition maxi-mum (RM; the maximum amount of weight one can lift in one repetition) by $5 \%$ and $10 \%$ increments when the patient could complete 15 repetitions comfortably. The prescribed exercises included lumbar extension, decline chest press, knee extension and flexion, pullovers, triceps extension, biceps flexion, shoulder press, and abdominal exercises. Results from the trial showed that both groups had significant declines in BMD from pre-transplantation to 2 months following trans-plantation $(p<0.05)$. The treatment group restored $99 \%$ of their total body BMD after 6 months of resistance training, while the control group had 7\% less total BMD $(p<0.05$ in between-group analysis versus control group at 6 months follow-up). Similarly, the femoral neck and lumbar BMD as well as measures of total $\mathrm{BMC}$ and calcium were returned to near baseline values for the treatment group versus a continuous decline in BMD at 3 and 6 months for the control group.

Braith and colleagues expanded on their initial study with HTRs to assess whether there was added benefit of resistance exercise training to bisphosphonates in a 3-arm RCT [106]. In this study, 25 HTRs were randomly assigned to receive bisphosphonate treatment (alendronate, $10 \mathrm{mg} /$ day), resistance exercise training plus bisphosphonate, or no treatment for 6 months. The exercise plus bisphosphonate group received the same exercise program as in Braith's original trial [107]. Participants in all three groups had significant reductions in total body, femoral neck, and lumbar spine BMD within 2 months of receiving the heart transplant prior to the intervention. At 3 and 6 months following the start of the intervention, the control group had continued to lose significant amounts of BMD, the bisphosphonate-only group had no further losses in BMD after initiation of treatment, whereas the bisphosphonate plus exercise group recovered almost all of their BMD to pre-transplantation levels.

The results of Dr. Braith's and his colleagues' work demonstrates the significant importance of an intensive, supervised resistance training program on BMD for HTR patients, which should be considered in standard cardiac rehabilitation. Unfortunately, little is known about the effect of common cardiac rehabilitation modalities (typically consisting of light-moderate intensity aerobic exercise) on bone health. Future studies in the field of cardiac rehabilitation, especially for HTRs, should consider using validated measures of BMD to assess potential changes in bone health.

\section{EXERCISE AND BONE HEALTH IN PATIENTS WITH ARTHRITIS}

While the etiology of rheumatoid arthritis and osteoarthritis are markedly different, the functional limitations, pain, and risk of osteoporotic fractures are similar and are discussed together [108-112]. Several studies have examined the effect of exercise on bone health for patients with rheumatoid arthritis that have provided conflicting findings [113-116]. Three, relatively small studies $(n=53-70)$ found little to no effect of aerobic or resistance training on bone outcomes for rheumatoid arthritis patients [113-115]. However, the general finding in these studies was that bone may be preserved, rather than improved, in exercising subjects compared to non-exercising controls but statistical significance was not achieved, likely due to sample sizes. In the largest exercise trial in this population to date, and one specifically powered to detect chronic bone changes, de Jong et al. randomized 309 rheumatoid arthritis patients to a highintensity, mixed-modality training program or a nonexercise, usual care control group [116]. Exercising subjects participated in twice-weekly, supervised group-exercise for 75 minutes per session, that included 20 minutes of stationary cycling, circuit training (8-10 exercises), and sport or game activities. Over the two year follow-up period, participants in the exercise group had less total hip bone decay than did control participants (mean between groups difference; mixed-effects ANOVA $\mathrm{p}=0.026$ ), but there was no difference in BMD at the lumbar spine.

For women with postmenopausal osteoarthritis, Song et al. (2010) recently examined the effects of a 6-month T'ai Chi program on muscle strength, BMD, and fear of falling. $T$ 'ai Chi represents an ideal modality for stimulating muscular strength and balance with implications for reducing falls [117]. In their RCT, intervention subjects received an arthritis-specific T'ai Chi program consisting of 31 forms of Sun-style T'ai Chi led by certified instructors for approxi- 
mately one-hour sessions and were encouraged to practice T'ai Chi for 20 minutes daily at home. Control group participants received a self-help education program for two hours each month. At the end of the intervention, T'ai Chi subjects had higher BMD scores at post-test than control subjects for femoral neck $(\mathrm{p}<0.01)$, Ward's triangle $(\mathrm{p}=0.02)$, and trochanter $(\mathrm{p}<0.01)$, as well as a reduced fear of falling $(p<0.01)$. This unique trial demonstrates the efficacy of alternative exercise modalities at maintaining bone health while providing further evidence that a lack of osteogenic stimulus via physical inactivity results in more rapid bone deterioration.

This literature on exercise for arthritic patients is compelling as two poignant studies describe exercises that are novel to patients with joint disease: T'ai Chi and high impact training. T'ai Chi has a number of inherent balancerelated benefits that can reduce fall risk; however its efficacy at improving hip BMD is novel and somewhat surprising given the low-impact nature of practice. On the other hand, high-intensity exercises that are often contraindicated for arthritic patients due to joint pain were also successful at maintaining hip BMD in patients with rheumatoid arthritis. The fact that BMD benefits have been observed across a spectrum of exercise interventions for arthritic patients is encouraging.

\section{EXERCISE AND BONE HEALTH DURING WEIGHT LOSS}

Obesity is an area of high interest for many exercise researchers due to its increased prevalence and association with chronic diseases and mortality [118-124]. However, obesity may be protective against osteoporosis due to increased skeletal loading and increased concentrations of bone remodeling hormones, such as estradiol [125-127]. While weight loss may be important for the prevention of a number of chronic diseases, a growing body of literature demonstrates that diet-induced weight loss is associated with concurrent reductions in BMD [128-130]. Accordingly, several researchers have sought ways to preserve bone during weight loss programs, often with the integration of exercise regimes [131-136]. Collectively, these studies suggest that bone loss may be attenuated with exercise.

Four RCTs have examined the effect of exercise as a bone-preserving weight loss modality [131-133, 135]. Two of these RCTs assessed bone outcomes using a 3-arm design: exercise-induced weight loss versus diet-induced weight loss versus no-weight loss control [132, 133]. Pritchard et al. conducted the first of these 3 -arm RCTs in 66 obese (BMI = $29 \pm 2.6 \mathrm{~kg} / \mathrm{m}^{2}$ ) men randomized to a low-fat diet, aerobic exercise $(65-75 \%$ of maximum heart rate), or a weight maintenance program (control) [133]. At 12 months, the two intervention groups had significantly less fat mass than controls, however, only the diet group had significant reductions in BMD $(\mathrm{p}<0.05)$ and BMC $(\mathrm{p}<0.001)$ (Pre- posttest percent change for exercise group: $\mathrm{BMC}=-0.8$; $\mathrm{BMD}$ : 1.1; for diet group: $\mathrm{BMC}=-1.4 ; \mathrm{BMD}=-1.5$ ). The exercise group had lower BMD and BMC than controls, but the difference was not significant. More recently, Villareal and colleagues conducted a similar trial in 48 overweight $(\mathrm{BMI}=$ $27 \pm 2 \mathrm{~kg} / \mathrm{m}^{2}$ ) men and women [132]. Comparable findings to the Pritchard et al. study were observed, as they noted reductions in weight, while only the exercise group maintained BMD at all DEXA-measured sites. The diet group had lost total hip $(-2.2 \%$ versus $1.2 \%, \mathrm{p}=0.02)$ and inter-trochanter $(-2.1 \%$ versus $1.7 \% ; \mathrm{p}=0.03) \mathrm{BMD}$ compared to the control group.

The studies by Pritchard and Villareal provide compelling evidence regarding the efficacy of exercise for BMD maintenance during a weight loss program when compared to weight loss achieved by diet alone. Ideally, diet and exercise may yield the greatest reduction in weight while preserving bone integrity. To examine this, Villareal and colleagues followed up their original trial with a 2-arm RCT comparing the effects of a multidimensional weight loss intervention (diet plus exercise plus behavioral change strategy) versus no treatment on BMD in 27 obese elders (mean BMI $>38$; mean age of 70 years) [131]. Their exercise program was designed to improve endurance, strength, balance, and BMD through 90-minute supervised, groupexercise sessions three days per week at a moderate to vigorous intensity (aerobic exercise: $75-90 \%$ of peak heart rate; resistance training: $65-80 \%$ of one RM). At the end of 12 months, the treatment group reduced their body weight by approximately $9 \%$ compared to controls $(p<0.01)$ but had concomitant reductions in BMD and $\mathrm{BMC}$ by $2-3 \%$ at the total hip, femoral neck, trochanter, and inter-trochanter compared to controls $(\mathrm{p}<0.05)$. Markers of bone remodeling (CTX and osteocalcin) were also significantly higher in the treatment group than in the control group, indicating higher bone-turnover. Similar findings were reported by Ryan et al. as they observed decreases in hip BMD in diet and diet-plusexercise groups in their non-randomized trial of 41 postmenopausal obese women [136].

A recent study by Silverman and colleagues has shown that BMD may actually be increased with aerobic exercise in 86 overweight and obese post-menopausal women participating in a weight loss program in a retrospective non-randomized study [134]. Their study compared participants in a weight loss program that did or did not include routine walking (at $50-75 \%$ of the heart rate reserve for $45-60$ minutes three days per week) for 6 months. While both groups experienced weight loss $(p<0.001)$, only those that were routinely walking experienced a $2 \%$ increase in femoral neck BMD ( $p=0.001)$, as well as a decrease in inflammatory markers (soluble Tumor Necrosis Factor 1 and interleukin-6) that are associated with bone resorption.

The effect of exercise on bone health during weight loss remains equivocal and requires further study. However, it appears that when compared to diet-induced weight loss, comparable exercise-induced weight loss results in less bone deterioration; but when diet and exercise are combined, bone loss is similar to that of diet alone and reductions in BMD are proportionate to reductions in weight [128-130, 137]. Recent research by Silverman et al. suggest that exercise may result in improvements in BMD during weight loss, but these results require confirmation from a RCT. Given the negative relationship between health and obesity, weight loss programs will likely remain a popular research field, but must consider the detrimental effects on bone health when designing interventions. 


\section{EXERCISE AND BONE HEALTH IN STROKE PATIENTS}

Chronic stroke patients are particularly vulnerable to fragility fractures due to prolonged inactivity, muscle weakness and loss of balance [138-141]. BMD is significantly reduced in the paretic limb $[142,143]$ and two studies have estimated that approximately $5 \%$ of stroke survivors experience a hip fracture within the first 3 years following a stroke [138, 139]. To counteract the bone loss, Pang et al. conducted a RCT in 63 chronic stroke patients assessing the effects of a 19-week intensive exercise intervention on BMD [144]. The community-based exercise program was designed to improve lower extremity bone strength, aerobic fitness, and balance using weight bearing, functional activities, such as brisk walking, sit to stand exercises, and step ups. As assessed by peripheral quantitative computed tomography, the experimental group showed a 5\% increase in distal tibial trabecular BMC in the paretic limb compared to the control group, which had a $0.5 \%$ loss in BMC $(p=0.048)$. No differences were found in the non-paretic limb. The effect of exercise on outcomes in this trial may have been blunted by exercise contamination in the non-intervention group, as they reported significant increases in physical activity over the course of the intervention. Given the limited amount of available evidence in this population, further studies are needed to confirm BMD and exercise relationships for stroke patients.

\section{DISCUSSION}

By 2025, the projected annual economic burden of osteoporotic-fractures is estimated to be more than $\$ 25$ billion (USD) [3]. With an aging population more susceptible to chronic medical illnesses, secondary osteoporosis is likely to become a greater contributor to fractures and fracture related costs. Thus, lifestyle approaches like exercise are becoming a more prevalent adjunct management strategy for patients with secondary osteoporosis. However, the overall dearth of literature in this field is surprising given the stated physical, social, and economic burden associated with fractures in clinical populations. Early findings in breast and prostate cancer, arthritis, stroke, heart transplantation, and weight loss studies require additional research to confirm early findings and to examine physiologic mechanisms of bone preservation given various possible disease and drug interactions with exercise and bone. Moreover, preliminary research with multiple sclerosis patients who are also susceptible to secondary osteoporosis, have preliminary research to suggest that exercise may improve fracture risk through physical fitness and physical activity [145]. However, intervention studies in these populations using bone outcomes are not available. Given the prevalence of secondary osteoporosis in numerous clinical populations, it is likely that exercise related research specifically for bone outcomes will expand considerably.

Preliminary evidence from trials reviewed in this paper indicates that exercise is safe and likely confers a modest attenuating effect on bone loss for those that have or are at risk for secondary osteoporosis. Whether or not exercise provides clinically important differences to bone health in clinical populations requires further study but some trials suggest that falls and fall-related fractures may be reduced in patients with age-related osteoporosis [54]. The most clinically relevant trials related to bone health, will likely be long-term, adequately-powered RCTs that examine the role of exercise and the incidence of falls and fractures. To date, most studies have been underpowered to assess bone outcomes, have had limited follow-up durations (median $=6$ months, maximum $=24$ months), utilized mild forms of exercise training, and have not thoroughly examined or reported on adherence and potential contamination (between intervention and control groups). However, this early body of literature generally does consist of RCT designs and acute/sub-acute follow-up periods that have shown promising effects of exercise on musculoskeletal characteristics that may confer a fracture risk reduction.

The most promising line of research is likely the continued examination of combined exercise and pharmacologic approaches to bone health as early studies in this field suggest a possible synergistic relationship [76, 106]. RANKL inhibitors and bisphosphonates have demonstrated significant benefit for patients in terms of BMD and fracture risk, however, drug side effects and treatment costs may be prohibitive for some patients. As such, a lifestyle intervention including calcium and vitamin $\mathrm{D}$ combined with exercise may be an optimal complimentary strategy for maintaining bone health. Two studies investigated the combined effects of exercise plus pharmacologic treatment for BMD versus pharmacologic treatment alone $[76,106]$. While exercise provided added benefits to bisphosphonates in both trials, neither study used a control group or an exercise-only group. A 2 × 2 factorial design RCT (exercise-only versus exercise plus drug versus drug-only versus control), is laborintensive and costly, but would provide the most detailed understanding of exercise and drug intervention approaches for clinical populations with compromised bone health.

Exercise interventions for secondary osteoporosis have largely consisted of mild forms of training (weight bearing, aerobic exercises, standard resistance training regimens, etc.). Future research should address the effectiveness of high-intensity weight bearing activities, plyometrics, and resistance exercise training protocols that have been shown to be the most effective training characteristics for bone development in healthy populations $[8,146-148]$ and can be safely conducted in participants that are in their late nineties [149]. While traditionally not employed in clinical populations, several studies highlighted in this paper show that high-intensity resistance training appears to be feasible and safe. Galvao et al. (2006) demonstrated the safety of a progressively intense resistance training protocol in prostate cancer patients with a mean age was 70 years and actively undergoing hormone ablation [95]. Newton and colleague's current trial, also with older, prostate cancer patients, employs a progressively intense plyometric-type intervention, including skipping, hurdle jumping, drop jumping, onelegged hopping, and leaping [96]. These studies will provide clarity to the types and intensity of exercise interventions that are safe, tolerable, and effective for maintaining and/or improving bone properties in what were previously considered frail or fragile populations.

Given the clinical significance of fractures, more longterm exercise trials that assess falls within clinical populations are required. The value of exercise in reducing falls and 
fractures extends beyond the effects on bone physiology but improves musculoskeletal endurance and strength, as well as balance and coordination. Additionally, epidemiologic studies that assess the success of public health agency recommendations in promoting physical activity for populations at risk of osteopenia and osteoporosis are needed to describe the efficacy of the campaigns and identify facilitators and barriers to exercise specifically for clinical populations. National agencies such as Health Canada and Osteoporosis Canada invest heavily in public campaigns attempting to increase the awareness of osteopenia and osteoporosis while strongly recommending physical activity and weight bearing

Table 1. Summary of the Proposed Mechanisms Leading to Reduced BMD or Fracture Risk

\begin{tabular}{|c|c|}
\hline Cause of Secondary Osteoporosis & Mechanisms of Decreased BMD and Increased Fracture Risk \\
\hline Cancer & $\begin{array}{c}\text { Osteosarcomas, metastatic lesions } \\
\text { Cancer-related fatigue } \rightarrow \downarrow \text { mobility, } \rightarrow \downarrow \text { PA }\end{array}$ \\
\hline $\begin{array}{l}\text { Cancer Treatment: Chemotherapy (e.g. } \\
\text { doxorubicin, methotrexate, cyclophosphamide) }\end{array}$ & $\begin{array}{c}\uparrow \text { bone resorption, } \downarrow \text { bone formation } \\
\downarrow \text { vitamin D metabolism, } \downarrow \text { calcium absorption }\end{array}$ \\
\hline Cancer Treatment: Radiation & $\begin{array}{c}\uparrow \text { calcium excretion } \rightarrow \downarrow \text { calcium absorption, } \uparrow \text { parathyroid hormone } \\
\downarrow \text { vitamin } \mathrm{D} \text { absorption, } \downarrow \text { calcium absorption } \\
\uparrow \text { osteoclast activation due to damage to bone marrow cells causing } \uparrow \text { inflammatory response }\end{array}$ \\
\hline Cancer Treatment: Hormonal Therapy - Males & $\begin{array}{c}\text { Hypogonadism } \rightarrow \downarrow \text { bioavailable testosterone } \rightarrow \uparrow \mathrm{R}: \mathrm{F} \\
\downarrow \text { lean mass } \rightarrow \uparrow \text { fall risk }\end{array}$ \\
\hline Cancer Treatment: Hormonal Therapy - Females & $\begin{array}{c}\text { Hypogonadism } \rightarrow \downarrow \text { bioavailable estrogen } \rightarrow \uparrow \mathrm{R}: \mathrm{F} \\
\text { Premature menopause (LHRHa, aromatase inhibitors) } \rightarrow \uparrow \mathrm{R}: \mathrm{F}\end{array}$ \\
\hline $\begin{array}{l}\text { Glucocorticoid use } \\
\text { (for cancer, heart transplantation, etc.) }\end{array}$ & $\begin{array}{c}\downarrow \text { vitamin D metabolism, } \downarrow \text { calcium absorption } \\
\uparrow \mathrm{R}: \mathrm{F} \rightarrow \downarrow \text { BMD } \\
\uparrow \text { muscular atrophy, } \downarrow \text { metabolic rate } \uparrow \text { metabolic disorders } \rightarrow \uparrow \text { Adiposity } \rightarrow \downarrow \text { PA }\end{array}$ \\
\hline Arthritis & $\begin{array}{c}\downarrow \text { Mobility, } \uparrow \text { Pain } \downarrow \text { Joint function } \rightarrow \downarrow \text { PA } \\
\text { Glucocorticoid use for RA (see above) }\end{array}$ \\
\hline Weight Loss & $\begin{array}{c}\downarrow \text { caloric intake }(\downarrow \text { calcium, } \downarrow \text { vitamin } \mathrm{D}) \\
\downarrow \text { estradiol } \rightarrow \uparrow \mathrm{R}: \mathrm{F} \\
\uparrow \mathrm{R}: \mathrm{F} \text { (all mechanisms are poorly understood) }\end{array}$ \\
\hline Stroke & $\begin{array}{c}\text { Prolonged inactivity/non-weight bearing } \rightarrow \text { Muscle atrophy } \rightarrow \downarrow \text { PA } \\
\downarrow \text { vitamin D exposure and intake, } \uparrow \text { bone resorption } \\
\downarrow \text { Balance } \rightarrow \uparrow \text { risk of falling }\end{array}$ \\
\hline
\end{tabular}

Table 2. Exercise Guidelines and Considerations for Patients with Secondary Osteoporosis

\begin{tabular}{|c|c|c|}
\hline $\begin{array}{l}\text { Condition Associated with } \\
\text { Secondary Osteoporosis }\end{array}$ & General Exercise Guidelines & $\begin{array}{c}\text { Exercise Considerations for Bone Health Promotion } \\
\text { with Respect to Underlying Morbidity }\end{array}$ \\
\hline CTIBL & $\begin{array}{l}\text { Frequency: } 4-7 \text { days per week } \\
\text { Intensity: AET }=50-80 \% \text { of } \mathrm{MHR} \text {; } \\
\text { RET }=50-75 \% \text { of } 1 \mathrm{RM} ; 2-3 \text { sets of } 8-12 \\
\text { repetitions } \\
\text { Time: } 15-60 \text { minutes per session } \\
\text { Type: large muscle groups with } \\
\text { consideration for localized disease and } \\
\text { treatment-related functional limitations }\end{array}$ & $\begin{array}{l}\text { - Information re: the type and duration of treatment(s) is necessary for fall and } \\
\text { fracture risk assessment; consider surgical grafts and various } \\
\text { musculoskeletal imbalances } \\
\text { - Information regarding bone metastasis is necessary to avoid heavy torque or } \\
\text { load in areas of metastatic disease } \\
\text { Exercise is generally symptom limited; symptoms may be localized or } \\
\text { - } \quad \text { Weightemic due to disease or treatment } \\
\text { independence and facilitate bone health } \\
\text { Balance training and lower extremity strength training is recommended to } \\
\text { prevent falls given reduced balance and peripheral neuropathies } \\
\text { Patient concern that post exercise-related discomfort is associated with } \\
\text { disease progression (i.e. metastatic bone pain) should be monitored and } \\
\text { referral to physician for bone examination may be warranted } \\
\text { Severe deconditioning can negatively affect balance and increase } \\
\text { fall/fracture risk; accordingly, balance should be trained and ambulatory } \\
\text { exercises should be monitored closely }\end{array}$ \\
\hline
\end{tabular}


(Table 2) Contd.....

\begin{tabular}{|c|c|c|}
\hline $\begin{array}{l}\text { Condition Associated with } \\
\text { Secondary Osteoporosis }\end{array}$ & General Exercise Guidelines & $\begin{array}{l}\text { Exercise Considerations for Bone Health Promotion } \\
\text { with Respect to Underlying Morbidity }\end{array}$ \\
\hline $\begin{array}{l}\text { Heart Transplant } \\
\text { Recipients }\end{array}$ & $\begin{array}{l}\text { Frequency: } 3-5 \text { days per week } \\
\text { Intensity: AET: RPE }=10-15 / 20 ; \\
\text { RET }=50-60 \% \text { of } 1 \mathrm{RM} ; 1-2 \text { sets of } 10-15 \\
\text { repetitions } \\
\text { Time: } 15-60 \text { minutes per session } \\
\text { Type: large muscle groups with } \\
\text { consideration for localized disease and } \\
\text { treatment-related functional limitations }\end{array}$ & $\begin{array}{l}\text { - } \quad \text { Review type and duration glucocorticoid use to assess risk of osteoporosis } \\
\text { - Severe systemic deconditioning is common and intervention intensity and } \\
\text { duration may be highly limited in early stages of exercise program } \\
\text { - } \quad \text { Subjective RPE should be used to monitor intensity rather than HR } \\
\text { Peripheral vascular disease and calf cramping is common and may result in } \\
\text { symptom limited ambulation; patients with this condition should exercise in } \\
\text { environments suitable to frequent rest periods } \\
\text { - Severe deconditioning can negatively affect balance and increase } \\
\text { fall/fracture risk; accordingly, balance should be trained and ambulatory } \\
\text { exercises should be monitored closely }\end{array}$ \\
\hline Arthritis & $\begin{array}{l}\text { Frequency: } 3-7 \text { days per week } \\
\text { Intensity: AET: } 60-80 \% \text { of MHR; RET= } \\
\text { limited by affected joint; use pain } \\
\text { tolerance to determine resistance for } 2-3 \\
\text { sets of } 8-12 \text { repetitions } \\
\text { Time: symptom-limited } \\
\text { Type: large muscle groups with } \\
\text { consideration for localized pain and } \\
\text { dysfunction; aquatic fitness may be } \\
\text { preferred; low impact exercises are } \\
\text { recommended }\end{array}$ & $\begin{array}{l}\text { - For arthritis affecting the hands, use resistance bands that can be wrapped } \\
\text { around hands rather than weights that may be too heavy for the patient to } \\
\text { hold; similarly, exercise machines may be preferable to free weights. } \\
\text { Gentle and partial weight bearing exercises (e.g. walking or pool-based } \\
\text { exercise) should be promoted rather than high-impact exercises that may } \\
\text { exacerbate the arthritic condition and pain, resulting in further inactivity } \\
\text { - Prolonged periods of sedentary behavior due to arthritic pain may result in } \\
\text { significant deconditioning and loss of balance; slow progression of exercise } \\
\text { program with balance training is recommended } \\
\text { Exercise may be preferable in the afternoon for rheumatoid arthritis patients } \\
\text { that experience morning stiffness } \\
\text { Monitor symptoms of pain and swelling associated with exercise; revise } \\
\text { exercise program accordingly }\end{array}$ \\
\hline Weight loss & $\begin{array}{l}\text { Frequency: } 4-7 \text { days per week } \\
\text { Intensity: AET: }=50-70 \% \text { MHR; } \\
\text { RET }=60-70 \% \text { of } 1 \mathrm{RM} ; 2-4 \text { sets of } 10-15 \\
\text { repetitions } \\
\text { Time: } 15-60 \text { minutes per session } \\
\text { Type: large muscle groups that result in } \\
\text { highest metabolic cost while } \\
\text { accommodating co-morbidities associated } \\
\text { with obesity/overweight (e.g. arthritis, } \\
\text { early onset of fatigue) }\end{array}$ & $\begin{array}{l}\text { - Low impact exercises may be preferred due to joint pain; consider pool- } \\
\text { based exercises that are only partial weight bearing; high-impact exercises } \\
\text { for the lower extremities should be avoided. } \\
\text { Equipment modification or alternative modality selection may be necessary } \\
\text { for using some RET or AET machines } \\
\text { - Consider caloric restriction interventions that may limit bioavailable energy } \\
\text { substrates and subsequently reduce exercise intensity or duration } \\
\text { Balance training and injury prevention is paramount to ensure exercise- } \\
\text { induced weight loss can continue; measures to prevent falls and overuse } \\
\text { injuries are recommended }\end{array}$ \\
\hline
\end{tabular}

AET $=$ aerobic exercise training; CTIBL $=$ cancer treatment-induced bone less; HR = heart rate; MHR = maximal heart rate; $\mathrm{RET}=$ resistance exercise training; RM = repetition maximum; RPE = rating of perceived exertion (scale of 6-20).

exercises for bone health[150]. The value of these campaigns will be challenged in the face of an aging population with sedentary lifestyles that heighten the risk for chronic disease and secondary osteoporosis. Population-based health outcome research, such as the Canadian Health Measures Survey, should include bone health, falls, and fracture data with concomitant collection of physical activity patterns that will enable researchers to assess long-term trends in bone health, relative to public campaigns designed to improve awareness of bone health issues.

\section{CONCLUSION}

Secondary osteoporosis is of growing interest to clinicians and researchers. Exercise has shown benefit in healthy populations and persons with primary osteoporosis. Accordingly, there is a movement in clinical exercise physiology to assess the value of exercise to assist in bone-related disorders secondary to various underlying pathologies and associated treatments. While the research is far from conclusive in this field, preliminary findings are promising and warrant further investigation. Campaigns that educate and promote physical activity within populations with chronic disease are justified given the strong evidence describing physical health benefits beyond bone health and fall risk. However, given the high importance and cost associated with bone health and falls, educational and interventional campaigns should specifically target patients who are at high risk for fragility fractures related to their condition or treatment. The studies presented in this paper 
describe the nascent, yet promising state of literature within the field and offer future directions for related research. Clinical exercise guidelines referring to bone preservation in various clinical groups should be updated with specific reference to bone-related outcome research in those areas. Specific research that builds on this preliminary evidence of the added effect of exercise to pharmacologic interventions, and the effectiveness of population-wide campaigns in preventing osteoporosis and fractures remain areas of high importance.

\section{CONFLICTS OF INTEREST}

The Authors have no conflicts of interest.

\section{ACKNOWLEDGEMENTS}

We would like to thank the following individuals for their support and assistance in the preparation of this manuscript: Michelle Nadler, Dr. Chris Ardern, Dr. Jane Irvine, Dr. Joel Katz and Dr. Mina Singh.

\section{REFERENCES}

[1] Cooper C. Epidemiology of osteoporosis. Osteoporos Int 1999; 9 (Suppl 2): S2-8.

[2] Holroyd C, Cooper C, Dennison E. Epidemiology of osteoporosis. Best Pract Res Clin Endocrinol Metab 2008; 22(5): 671-85.

[3] Burge R, Dawson-Hughes B, Solomon DH, Wong JB, King A, Tosteson A. Incidence and economic burden of osteoporosisrelated fractures in the United States, 2005-2025. J Bone Miner Res 2007; 22(3): 465-75.

[4] Kelley GA, Kelley KS, Tran ZV. Exercise and bone mineral density in men: a meta-analysis. J Appl Physiol 2000; 88(5): 17306.

[5] Kelley GA, Kelley KS, Tran ZV. Resistance training and bone mineral density in women: a meta-analysis of controlled trials. Am J Phys Med Rehabil 2001; 80(1): 65-77.

[6] MacKelvie KJ, Khan KM, Petit MA, Janssen PA, McKay HA. A school-based exercise intervention elicits substantial bone health benefits: a 2-year randomized controlled trial in girls. Pediatrics 2003; $112(6$ Pt 1): e447.

[7] MacKelvie KJ, McKay HA, Petit MA, Moran O, Khan KM. Bone mineral response to a 7-month randomized controlled, school-based jumping intervention in 121 prepubertal boys: associations with ethnicity and body mass index. J Bone Miner Res 2002; 17(5): 83444.

[8] Martyn-St James M, Carroll S. High-intensity resistance training and postmenopausal bone loss: a meta-analysis. Osteoporos Int 2006; 17(8): 1225-40.

[9] Petit MA, McKay HA, MacKelvie KJ, Heinonen A, Khan KM, Beck TJ. A randomized school-based jumping intervention confers site and maturity-specific benefits on bone structural properties in girls: a hip structural analysis study. J Bone Miner Res 2002; 17(3): 363-72.

[10] Kohrt WM, Bloomfield SA, Little KD, Nelson ME, Yingling VR. American College of Sports Medicine Position Stand: Physical activity and bone health. Med Sci Sports Exerc 2004; 36(11): 198596.

[11] Khan K, McKay H, Kannus P, Bailey D, Wark J, Bennell K. Physical activity and bone health. Windsor: Human Kinetics; 2001.

[12] Turner $\mathrm{CH}$, Robling AG. Designing exercise regimens to increase bone strength. Exerc Sport Sci Rev 2003; 31(1): 45-50.

[13] Painter SE, Kleerekoper M, Camacho PM. Secondary osteoporosis: a review of the recent evidence. Endocr Pract 2006; 12(4): 436-45.

[14] Rosen CJ. Pathophysiology of osteoporosis. Clin Lab Med 2000; 20(3): 455-68

[15] Johnston CC, Jr., Slemenda CW. Pathogenesis of osteoporosis. Bone 1995; 17(Suppl 2): 19S-22S.
[16] Michaud LB, Goodin S. Cancer-treatment-induced bone loss, part 2. Am J Health Syst Pharm 2006; 63(6): 534-46.

[17] Michaud LB, Goodin S. Cancer-treatment-induced bone loss, part 1. Am J Health Syst Pharm 2006; 63(5): 419-30.

[18] Kanis JA, Melton LJ, 3rd, Christiansen C, Johnston CC, Khaltaev N. The diagnosis of osteoporosis. J Bone Miner Res 1994; 9(8): $1137-41$.

[19] Assessment of fracture risk and its application to screening for postmenopausal osteoporosis. Report of a WHO Study Group. World Health Organization Technical Report Series. 1994; 843: 1129.

[20] WHO Fracture Risk Assessment Tool. [homepage on the Internet] Shefflield: World Health Organization Collaborating Centre for Metabolic Bone Diseases; c2011[cited 2010 November 18, 2010]; Available from: http://www.shef.ac.uk/FRAX/.

[21] Basaria S, Lieb J, $2^{\text {nd }}$, Tang $A M$, et al. Long-term effects of androgen deprivation therapy in prostate cancer patients. Clin Endocrinol 2002; 56: 779-86.

[22] Leder BZ, LeBlanc KM, Schoenfeld DA, Eastell R, Finkelstein JS. Differential effects of androgens and estrogens on bone turnover in normal men. J Clin Endocrinol Metab 2003; 88(1): 204-10.

[23] Riggs BL. The mechanisms of estrogen regulation of bone resorption. J Clin Invest 2000; 106(10): 1203-4.

[24] Shahinian VB, Yong-Fang K, Freeman JL, Goodwin JS. Risk of fracture after androgen deprivation for prostate cancer. N Engl J Med 2005; 352: 154-64.

[25] Smith MR, Finkelstein JS, McGovern FJ, et al. Changes in body composition during androgen deprivation therapy for prostate cancer. J Clin Endocrinol Metab 2002; 87(2): 599-603.

[26] Vehmanen L, Elomaa I, Blomqvist C, Saarto T. Tamoxifen treatment after adjuvant chemotherapy has opposite effects on bone mineral density in premenopausal patients depending on menstrual status. J Clin Oncol 2006; 24(4): 675-80.

[27] Allport J. Incidence and prevalence of medication-induced osteoporosis: evidence-based review. Curr Opin Rheumatol 2008; 20(4): 435-41.

[28] Boling EP. Secondary osteoporosis: Underlying disease and the risk for glucocorticoid-induced osteoporosis. Clin Ther 2004; 26(1): 1-14.

[29] Canalis E, Mazziotti G, Giustina A, Bilezikian JP. Glucocorticoidinduced osteoporosis: pathophysiology and therapy. Osteoporos Int 2007; 18(10): 1319-28.

[30] Bauer DC, Ettinger B, Nevitt MC, Stone KL. Risk for fracture in women with low serum levels of thyroid-stimulating hormone. Ann Intern Med 2001; 134(7): 561-8.

[31] Cummings SR, Nevitt MC, Browner WS, et al. Risk factors for hip fracture in white women. Study of Osteoporotic Fractures Research Group. N Engl J Med 1995; 332(12): 767-73.

[32] Heemstra KA, Hamdy NA, Romijn JA, Smit JW. The effects of thyrotropin-suppressive therapy on bone metabolism in patients with well-differentiated thyroid carcinoma. Thyroid 2006; 16(6): 583-91.

[33] Sissons HA. The osteoporosis of Cushing's Syndrome. J Bone Joint Surg Br 1956; 38-B(1): 418-33.

[34] Chiodini I, Torlontano M, Carnevale V, Trischitta V, Scillitani A. Skeletal involvement in adult patients with endogenous hypercortisolism. J Endocrinol Invest 2008; 31(3): 267-76.

[35] Räkel A, Sheehy O, Rahme E, LeLorier J. Osteoporosis among patients with type 1 and type 2 diabetes. Diabetes Metab 2008; 34(3): 193-205.

[36] Hofbauer LC, Brueck CC, Singh SK, Dobnig H. Osteoporosis in patients with diabetes mellitus. J Bone Miner Res 2007; 22(9): 1317-28.

[37] Fitzpatrick LA. Secondary causes of osteoporosis. Mayo Clin Proc 2002; 77(5): 453-68

[38] Harper KD, Weber TJ. Secondary osteoporosis. Diagnostic considerations. Endocrinol Metab Clin North Am 1998; 27(2): 32548 .

[39] Hofbauer LC, Hamann C, Ebeling PR. Approach to the patient with secondary osteoporosis. Eur J Endocrinol 2010; 162(6): 1009-20.

[40] Orlic ZC, Raisz LG. Causes of secondary osteoporosis. J Clin Densitom 1999; 2(1): 79-92

[41] Sikon AL, Thacker HL, Carey J, Deal C, Licata AA. Secondary osteoporosis: are we recognizing it? J Womens Health (Larchmt) 2006; 15(10): 1174-83. 
[42] Stein E, Shane E. Secondary osteoporosis. Endocrinol Metab Clin North Am 2003; 32(1): 115-34.

[43] Hosking DJ, Geusens P, Rizzoli R. Osteoporosis therapy: an example of putting evidence-based medicine into clinical practice. QJM 2005; 98(6): 403-13.

[44] Smith MR. Bisphosphonates to prevent osteoporosis in men receiving androgen deprivation therapy for prostate cancer. Drugs Aging 2003; 20(3): 175-83.

[45] Smith MR. Osteoclast targeted therapy for prostate cancer: bisphosphonates and beyond. Urol Oncol 2008; 26(4): 420-5.

[46] Gnant M. Management of bone loss induced by aromatase inhibitors. Cancer Invest 2006; 24(3): 328-30.

[47] Molina JR, Barton DL, Loprinzi CL. Chemotherapy-Induced ovarian failure: Manifestations and management. Drug Saf 2005; 28(5): 401-16.

[48] Saarto T. Adjuvant therapy of breast cancer - Bisphosphonates. In: Castiglione M, Piccart MJ, Eds. Adjuvant Therapy for Breast Cancer. US: Springer 2009; pp. 163-77.

[49] Smith MR, Egerdie B, Toriz NH, Feldman R, Tammela TLJ, Saad $\mathrm{F}$, et al. Denosumab in men receiving androgen-deprivation therapy for prostate cancer. N Eng J Med 2009; 361(8): 745-55.

[50] Muir VJ, Scott LJ. Denosumab: In cancer treatment-induced bone loss. BioDrugs 2010; 24(6): 379-86.

[51] Ellis GK, Bone HG, Chlebowski R, et al. Randomized trial of denosumab in patients receiving adjuvant aromatase inhibitors for nonmetastatic breast cancer. J Clin Oncol 2008; 26(30): 4875-82.

[52] MacLean C, Newberry S, Maglione M, et al. Systematic review: Comparative effectiveness of treatments to prevent fractures in men and women with low bone density or osteoporosis. Ann Intern Med 2008; 148(3): 197-213.

[53] Homik J, Suarez-Almazor ME, Shea B, Cranney A, Wells GA, Tugwell P. Calcium and vitamin D for corticosteroid-induced osteoporosis. Cochrane Database Syst Rev 1998; 2: 1-10.

[54] de Kam D, Smulders E, Weerdesteyn V, Smits-Engelsman BC. Exercise interventions to reduce fall-related fractures and their risk factors in individuals with low bone density: a systematic review of randomized controlled trials. Osteoporos Int 2009; 20(12): 211125 .

[55] Smith SS, Wang CE, Bloomfield SA. Osteoporosis. In: Durstine JL, Moore GE, Painter PL, Roberts SO, Eds. ACSM's exercise management for persons with chronic diseases and disabilities. 3rd ed. Champaign, IL: Human Kinetics 2009; pp. 270-7.

[56] Brufsky AM. Cancer treatment-induced bone loss: pathophysiology and clinical perspectives. Oncologist 2008; 13(2): 187-95.

[57] Pfeilschifter J, Diel IJ. Osteoporosis due to cancer treatment: pathogenesis and management. J Clin Oncol 2000; 18(7): 1570-93.

[58] Demark-Wahnefried W, Peterson BL, Winer EP, et al. Changes in weight, body composition, and factors influencing energy balance among premenopausal breast cancer patients receiving adjuvant chemotherapy. J Clin Oncol 2001; 19(9): 2381-9.

[59] Ali PA, al-Ghorabie FH, Evans CJ, el-Sharkawi AM, Hancock DA. Body composition measurements using DXA and other techniques in tamoxifen-treated patients. Appl Radiat Isot 1998; 49(5-6): 6435 .

[60] Irwin ML, McTiernan A, Baumgartner RN, et al. Changes in body fat and weight after a breast cancer diagnosis: influence of demographic, prognostic, and lifestyle factors. J Clin Oncol 2005; 23(4): 774-82.

[61] Kroenke CH, Chen WY, Rosner B, Holmes MD. Weight, weight gain, and survival after breast cancer diagnosis. J Clin Oncol 2005; 23(7): 1370-8.

[62] McInnes JA, Knobf MT. Weight gain and quality of life in women treated with adjuvant chemotherapy for early-stage breast cancer. Oncol Nurs Forum 2001; 28(4): 675-84.

[63] Goodwin PJ, Ennis M, Pritchard KI, Trudeau M, Hood N. Risk of menopause during the first year after breast cancer diagnosis. J Clin Oncol 1999; 17(8): 2365-70.

[64] Chen Z, Maricic M, Pettinger M, et al. Osteoporosis and rate of bone loss among postmenopausal survivors of breast cancer. Cancer 2005; 104(7): 1520-30.

[65] Shapiro CL, Manola J, Leboff M. Ovarian failure after adjuvant chemotherapy is associated with rapid bone loss in women with early-stage breast cancer. J Clin Oncol 2001; 19(14): 3306-11.

[66] Eastell R, Hannon RA, Cuzick J, Dowsett M, Clack G, Adams JE. Effect of an aromatase inhibitor on bmd and bone turnover markers: 2-year results of the anastrozole, tamoxifen, alone or in combination (ATAC) trial (18233230). J Bone Miner Res 2006; 21(8): 1215-23.

[67] Rosen CJ. Pathogenesis of osteoporosis. Baillieres Best Pract Res Clin Endocrinol Metab 2000; 14(2): 181-93.

[68] Seeman E. Pathogenesis of bone fragility in women and men. Lancet 2002; 359(9320): 1841-50.

[69] McNeely ML, Campbell KL, Rowe BH, Klassen TP, Mackey JR, Courneya KS. Effects of exercise on breast cancer patients and survivors: a systematic review and meta-analysis. Can Med Assoc J 2006; 175(1): 34-41

[70] Speck RM, Courneya KS, Masse LC, Duval S, Schmitz KH. An update of controlled physical activity trials in cancer survivors: a systematic review and meta-analysis. J Cancer Surviv 2010; 4(2): 87-100.

[71] Irwin ML, Alvarez-Reeves M, Cadmus L, et al. Exercise improves body fat, lean mass, and bone mass in breast cancer survivors. Obesity (Silver Spring) 2009; 17(8): 1534-41.

[72] Knobf MT, Insogna K, DiPietro L, Fennie C, Thompson AS. An aerobic weight-loaded pilot exercise intervention for breast cancer survivors: bone remodeling and body composition outcomes. Biol Res Nurs 2008; 10(1): 34-43.

[73] Rogers LQ, Hopkins-Price P, Vicari S, et al. A randomized trial to increase physical activity in breast cancer survivors. Med Sci Sports Exerc 2009; 41(4): 935-46.

[74] Swenson KK, Nissen MJ, Anderson E, Shapiro A, Schousboe J, Leach J. Effects of exercise vs bisphosphonates on bone mineral density in breast cancer patients receiving chemotherapy. J Support Oncol 2009; 7(3): 101-7.

[75] Waltman NL, Twiss JJ, Ott CD, et al. Testing an intervention for preventing osteoporosis in postmenopausal breast cancer survivors. J Nurs Scholarsh 2003; 35(4): 333-8.

[76] Waltman NL, Twiss JJ, Ott CD, et al. The effect of weight training on bone mineral density and bone turnover in postmenopausal breast cancer survivors with bone loss: a 24-month randomized controlled trial. Osteoporos Int 2010;21(8): 1361-9.

[77] Winters-Stone KM, Dobek J, Nail L, et al. Strength training stops bone loss and builds muscle in postmenopausal breast cancer survivors: a randomized, controlled trial. Breast Cancer Res Treat 2011; 127(2): 447-56.

[78] Schwartz AL, Winters-Stone K, Gallucci B. Exercise effects on bone mineral density in women with breast cancer receiving adjuvant chemotherapy. Oncol Nurs Forum 2007; 34(3): 627-33.

[79] Matthews CE, Wilcox S, Hanby CL, et al. Evaluation of a 12-week home-based walking intervention for breast cancer survivors. Support Care Cancer 2007; 15(2): 203-11.

[80] Schmitz KH, Ahmed RL, Hannan PJ, Yee D. Safety and efficacy of weight training in recent breast cancer survivors to alter body composition, insulin, and insulin-like growth factor axis proteins. Cancer Epidemiol Biomarkers Prev 2005; 14(7): 1672-80.

[81] Alibhai SMH, Gogov S, Allibhai Z. Long-term side effects of androgen deprivation therapy in men with non-metastatic prostate cancer: A systematic literature review. Critic Rev Oncol Hematol 2006; 60: 201-15.

[82] Greenspan SL, Coates P, Sereika SM, Nelson JB, Trump DL, Resnick NM. Bone loss after initiation of androgen deprivation therapy in patients with prostate cancer. J Clin Endocrinol Metab 2005; 90(12): 6410-7.

[83] Stoch SA, Parker RA, Chen L, et al. Bone loss in men with prostate cancer treated with gonadotropin-releasing hormone agonists. J Clin Endocrinol Metab 2001; 86: 2787-91.

[84] Daniell HW. Osteoporosis after orchiectomy for prostate cancer. J Urol 1997; 157: 493-44.

[85] Daniell HW, Dunn SR, Ferguson DW, Lomas G, Niazi Z, Stratte PT. Progressive osteoporosis during androgen deprivation therapy for prostate cancer. J Urol 2000; 163: 181-6.

[86] Mittan D, Lee S, Miller E, Perez RC, Basler JW, Bruder JM. Bone loss following hypogonadism in men with prostate cancer treated with GnRH analogs. J Clin Endocrinol Metab 2002; 87(8): 365661 .

[87] Saylor PJ, Keating NL, Smith MR. Prostate cancer survivorship: prevention and treatment of the adverse effects of androgen deprivation therapy. J Gen Intern Med 2009; 24 (Suppl 2): S38994.

[88] Preston DM, Torrens JI, Harding P, Howard RS, Duncan WE, McLeod DG. Androgen deprivation in men with prostate cancer is 
associated with an increased rate of bone loss. Prostate Cancer Prostatic Dis 2002; 5: 304-10.

[89] Oefelein MG, Ricchuiti V, Conrad W, et al. Skeletal fracture associated with androgen suppression induced osteoporosis: the clinical incidence and risk factors for patients with prostate cancer. J Urol 2001; 166(5): 1724-8.

[90] Oefelein MG, Ricchiuti V, Conrad W, Resnick MI. Skeletal fractures negatively correlate with overall survival in men with prostate cancer. J Urol 2002; 168(3): 1005-7.

[91] Allain TJ. Prostate cancer, osteoporosis and fracture risk. Gerontology 2006; 52(2): 107-10.

[92] Orwoll E, Ettinger M, Weiss S, et al. Alendronate for the treatment of osteoporosis in men. N Eng J Med 2000; 343(9): 604-10.

[93] Panju AH, Breunis $\mathrm{H}$, Cheung AM, et al. Management of decreased bone mineral density in men starting androgendeprivation therapy for prostate cancer. BJU Int 2009; 103(6): 7537.

[94] Alibhai SMH, Rahman S, Warde PR, Jewett MA, Jaffer T, Cheung AM. Prevention and management of osteoporosis in men receiving androgen deprivation therapy: A survey of urologists and radiation oncologists. Urology 2006; 68: 126-31.

[95] Galvao DA, Nosaka K, Taaffe DR, et al. Resistance training and reduction of treatment side effects in prostate cancer patients. Med Sci Sport Exerc 2006; 38(12): 2045-52.

[96] Newton RU, Taaffe DR, Spry N, et al. A phase III clinical trial of exercise modalities on treatment side-effects in men receiving therapy for prostate cancer. BMC Cancer 2009; 9: 210.

[97] Galvao DA, Taaffe DR, Spry N, Joseph D, Newton RU. Combined resistance and aerobic exercise program reverses muscle loss in men undergoing androgen suppression therapy for prostate cancer without bone metastases: a randomized controlled trial. J Clin Oncol 2010; 28(2): 340-7.

[98] Segal RJ, Reid RD, Courneya KS, et al. Randomized controlled trial of resistance or aerobic exercise in men receiving radiation therapy for prostate cancer. J Clin Oncol 2009; 27(3): 344-51.

[99] Boot AM, van den Heuvel-Eibrink MM, Hahlen K, Krenning EP, de Muinck Keizer-Schrama SM. Bone mineral density in children with acute lymphoblastic leukaemia. Eur J Cancer 1999; 35(12): 1693-7.

[100] Atkinson SA, Halton JM, Bradley C, Wu B, Barr RD. Bone and mineral abnormalities in childhood acute lymphoblastic leukemia: influence of disease, drugs and nutrition. Int J Cancer Suppl 1998; 11: 35-9.

[101] Hartman A, te Winkel ML, van Beek RD, et al. A randomized trial investigating an exercise program to prevent reduction of bone mineral density and impairment of motor performance during treatment for childhood acute lymphoblastic leukemia. Pediatr Blood Cancer 2009; 53(1): 64-71.

[102] Shane E, Rivas MC, Silverberg SJ, Kim TS, Staron RB, Bilezikian JP. Osteoporosis after cardiac transplantation. Am J Med 1993; 94(3): 257-64

[103] Berguer DG, Krieg MA, Thiebaud D, et al. Osteoporosis in heart transplant recipients: a longitudinal study. Transplant Proc 1994; 26(5): 2649-51.

[104] Rich GM, Mudge GH, Laffel GL, LeBoff MS. Cyclosporine A and prednisone-associated osteoporosis in heart transplant recipients. J Heart Lung Transplant 1992; 11(5): 950-8.

[105] Klein RG, Arnaud SB, Gallagher JC, Deluca HF, Riggs BL. Intestinal calcium absorption in exogenous hypercortisonism. Role of 25-hydroxyvitamin D and corticosteroid dose. J Clin Invest 1977; 60(1): 253-9.

[106] Braith RW, Magyari PM, Fulton MN, Aranda J Jr, Walker T, Hill $\mathrm{JA}$. Resistance exercise training and alendronate reverse glucocorticoid-induced osteoporosis in heart transplant recipients. J Heart Lung Transplant 2003; 22(10): 1082-90.

[107] Braith RW, Graves JE, Leggett SH, Pollock ML. Effect of training on the relationship between maximal and submaximal strength. Med Sci Sports Exerc 1993; 25: 132-8.

[108] Arden NK, Griffiths GO, Hart DJ, Doyle DV, Spector TD. The association between osteoarthritis and osteoporotic fracture: the Chingford Study. Br J Rheumatol 1996; 35(12): 1299-304

[109] Jones G, Nguyen T, Sambrook PN, Lord SR, Kelly PJ, Eisman JA. Osteoarthritis, bone density, postural stability, and osteoporotic fractures: a population based study. J Rheumatol 1995; 22(5): 9215.
[110] Celiker R, Gokce-Kutsal Y, Cindas A, et al. Osteoporosis in rheumatoid arthritis: effect of disease activity. Clin Rheum 1995; 14(4): 429-33.

[111] Hansen M, Florescu A, Stoltenberg M, et al. Bone loss in rheumatoid arthritis. Influence of disease activity, duration of the disease, functional capacity, and corticosteroid treatment. Scand J Rheumatol 1996; 25(6): 367-76.

[112] Gough AK, Lilley J, Eyre S, Holder RL, Emery P. Generalised bone loss in patients with early rheumatoid arthritis. Lancet 1994; 344(8914): 23-7.

[113] Westby MD, Wade JP, Rangno KK, Berkowitz J. A randomized controlled trial to evaluate the effectiveness of an exercise program in women with rheumatoid arthritis taking low dose prednisone. J Rheumatol 2000; 27(7): 1674-80.

[114] Hakkinen A, Sokka T, Kotaniemi A, et al. Dynamic strength training in patients with early rheumatoid arthritis increases muscle strength but not bone mineral density. J Rheumatol 1999; 26(6): 1257-63.

[115] Hakkinen A, Sokka T, Kotaniemi A, Hannonen P. A randomized two-year study of the effects of dynamic strength training on muscle strength, disease activity, functional capacity, and bone mineral density in early rheumatoid arthritis. Arthritis Rheum 2001; 44(3): 515-22.

[116] de Jong Z, Munneke M, Lems WF, et al. Slowing of bone loss in patients with rheumatoid arthritis by long-term high-intensity exercise: results of a randomized, controlled trial. Arthritis Rheum 2004; 50(4): 1066-76.

[117] Song R, Roberts BL, Lee EO, Lam P, Bae SC. A randomized study of the effects of t'ai chi on muscle strength, bone mineral density, and fear of falling in women with osteoarthritis. J Altern Complement Med 2010; 16(3): 227-33.

[118] Flegal KM, Carroll MD, Ogden CL, Curtin LR. Prevalence and trends in obesity among US adults, 1999-2008. JAMA 2010; 303(3): 235-41.

[119] Berghofer A, Pischon T, Reinhold T, Apovian CM, Sharma AM, Willich SN. Obesity prevalence from a European perspective: a systematic review. BMC Public Health 2008; 8: 200.

[120] Muller-Riemenschneider F, Reinhold T, Berghofer A, Willich SN. Health-economic burden of obesity in Europe. Eur J Epidemiol 2008; 23(8): 499-509.

[121] Cai L, Lubitz J, Flegal KM, Pamuk ER. The predicted effects of chronic obesity in middle age on medicare costs and mortality. Med Care 2010; 48(6): 510-7.

[122] Flegal KM, Graubard BI, Williamson DF, Gail MH. Cause-specific excess deaths associated with underweight, overweight, and obesity. JAMA 2007; 298(17): 2028-37.

[123] Ogden CL, Yanovski SZ, Carroll MD, Flegal KM. The epidemiology of obesity. Gastroenterology 2007; 132(6): 2087 102.

[124] Telford RD. Low physical activity and obesity: causes of chronic disease or simply predictors? Med Sci Sports Exerc 2007; 39(8): 1233-40.

[125] Shapses SA, Riedt CS. Bone, body weight, and weight reduction: what are the concerns? J Nutr 2006; 136(6): 1453-6.

[126] Bacon L, Stern JS, Keim NL, Van Loan MD. Low bone mass in premenopausal chronic dieting obese women. Eur J Clin Nutr 2004; 58(6): 966-71.

[127] Reid IR. Relationships among body mass, its components, and bone. Bone 2002; 31(5): 547-55.

[128] Chao D, Espeland MA, Farmer D, et al. Effect of voluntary weight loss on bone mineral density in older overweight women. J Am Geriatr Soc 2000; 48(7): 753-9.

[129] Jensen LB, Quaade F, Sorensen OH. Bone loss accompanying voluntary weight loss in obese humans. J Bone Miner Res 1994; 9(4): 459-63.

[130] Villareal DT, Fontana L, Weiss EP, et al. Bone mineral density response to caloric restriction-induced weight loss or exerciseinduced weight loss: a randomized controlled trial. Arch Intern Med 2006; 166(22): 2502-10.

[131] Villareal DT, Shah K, Banks MR, Sinacore DR, Klein S. Effect of weight loss and exercise therapy on bone metabolism and mass in obese older adults: a one-year randomized controlled trial. J Clin Endocrinol Metab 2008; 93(6): 2181-7.

[132] Villareal DT, Banks M, Sinacore DR, Siener C, Klein S. Effect of weight loss and exercise on frailty in obese older adults. Arch Intern Med 2006; 166(8): 860-6. 
[133] Pritchard JE, Nowson CA, Wark JD. Bone loss accompanying dietinduced or exercise-induced weight loss: a randomised controlled study. Int J Obes Relat Metab Disord 1996; 20(6): 513-20.

[134] Silverman NE, Nicklas BJ, Ryan AS. Addition of aerobic exercise to a weight loss program increases BMD, with an associated reduction in inflammation in overweight postmenopausal women. Calcif Tissue Int 2009; 84(4): 257-65.

[135] Chubak J, Ulrich CM, Tworoger SS, et al. Effect of exercise on bone mineral density and lean mass in postmenopausal women. Med Sci Sports Exerc 2006; 38(7): 1236-44.

[136] Ryan AS, Nicklas BJ, Dennis KE. Aerobic exercise maintains regional bone mineral density during weight loss in postmenopausal women. J Appl Physiol 1998; 84(4): 1305-10.

[137] Jensen LB, Kollerup G, Quaade F, Sorensen OH. Bone minerals changes in obese women during a moderate weight loss with and without calcium supplementation. J Bone Miner Res 2001; 16(1): 141-7.

[138] Kanis J, Oden A, Johnell O. Acute and long-term increase in fracture risk after hospitalization for stroke. Stroke 2001; 32(3): 702-6.

[139] Dennis MS, Lo KM, McDowall M, West T. Fractures after stroke: frequency, types, and associations. Stroke 2002; 33(3): 728-34.

[140] Hsu AL, Tang PF, Jan MH. Analysis of impairments influencing gait velocity and asymmetry of hemiplegic patients after mild to moderate stroke. Arch Phys Med Rehabil 2003; 84(8): 1185-93.

[141] Poole KE, Reeve J, Warburton EA. Falls, fractures, and osteoporosis after stroke: time to think about protection? Stroke 2002; 33(5): 1432-6.

[142] Jorgensen L, Jacobsen BK. Changes in muscle mass, fat mass, and bone mineral content in the legs after stroke: a 1 year prospective study. Bone 2001; 28(6): 655-9.
[143] Ramnemark A, Nyberg L, Lorentzon R, Englund U, Gustafson Y. Progressive hemiosteoporosis on the paretic side and increased bone mineral density in the nonparetic arm the first year after severe stroke. Osteoporos Int 1999; 9(3): 269-75.

[144] Pang MY, Ashe MC, Eng JJ, McKay HA, Dawson AS. A 19-week exercise program for people with chronic stroke enhances bone geometry at the tibia: a peripheral quantitative computed tomography study. Osteoporos Int 2006; 17(11): 1615-25.

[145] Steffensen LH, Mellgren SI, Kampman MT. Predictors and prevalence of low bone mineral density in fully ambulatory persons with multiple sclerosis. J Neurol 2010; 257(3): 410-8.

[146] Cheng S, Sipila S, Taaffe DR, Puolakka J, Suominen H. Change in bone mass distribution induced by hormone replacement therapy and high-impact physical exercise in post-menopausal women. Bone 2002; 31(1): 126-35.

[147] Maddalozzo GF, Snow CM. High Intensity resistance training: effects on bone in older men and women. Calcif Tissue Int 2000; 66(6): 399-404.

[148] Dornemann TM, McMurray RG, Renner JB, Anderson JJ. Effects of high-intensity resistance exercise on bone mineral density and muscle strength of 40-50-year-old women. J Sports Med Phys Fitness 1997; 37(4): 246-51.

[149] Fiatarone MA, Marks EC, Ryan ND, Meredith CN, Lipsitz LA, Evans WJ. High-intensity strength training in nonagenarians: effects on skeletal muscle. JAMA 1990; 263(22): 3029-34.

[150] Osteoporosis Canada. [homepage on the Internet]. Osteoporosis Canada (C); 2010 [updated 2011; cited 2010 November 18, 2010]; Available from: http://www.osteoporosis.ca/ 